\title{
The optimum refurbishment time of shopping centres
}

\author{
M Mushirivindi \\ D A Prinsloo \\ C E Cloete \\ Department of Construction Economics \\ University of Pretoria, South Africa
}

\section{Key words}

Refurbishment, shopping centre, renewal, redevelopment, life cycle, revamp, maintenance, asset enhancement, renovation, demolish.

\begin{abstract}
The optimum time in the life cycle of a shopping centre when refurbishment must be undertaken was investigated, based upon the analysis of three shopping centres in Durban, South Africa, which were older than thirty years and where refurbishment had not taken place for at least twelve years. To determine the impact of age on the centres' performance, data was gathered from shoppers, tenants and the landlords.

The results indicate that the life cycle stage, rather than physical age, plays a dominant role in determining the requirement to refurbish. Respondents prefer shorter periods (seven to ten years) between revamps to ensure that the shopping centre remains attractive to tenants and shoppers and rewarding in terms of financial returns to investors. The findings further indicated that the timing for refurbishment is moderated by internal factors such as management competency, investor strategy and feasibility of the refurbishment project as well as by external factors such as competition, market, social and technological environment. It has also been established that refurbishment must meet certain expected financial returns in order for it to be undertaken.

This paper demonstrates the importance of understanding the stage of the shopping centre in the product life cycle and ensuring that refurbishment is undertaken when it is due before loss of competitiveness and financial returns occur.
\end{abstract}

Corresponding author: C. E Cloete

Email address for corresponding author: chris.cloete@up.ac.za

First submission received: $11^{\text {th }}$ January 2018

Revised submission received: $5^{\text {th }}$ March 2018

Accepted: 25 $5^{\text {th }}$ March 2018

\section{Introduction}

A shopping centre is "...a group of architecturally unified commercial establishments built on a site which is planned, developed, owned and managed as an operating unit related to its location, size and type of shops to the trade area that the unit serves..." (Cloete. 2015: 118). The Australian Property Institute (2016:57) mentions that "a building that was functionally adequate at the time of construction can become inadequate or less appealing as design standards, mechanical systems and construction materials change over time". The physical state of the shopping centre plays a significant role in meeting the demands of space users, shoppers and achievement of investor's objectives. It is therefore integral for facilities to remain relevant in meeting the dynamic needs of users. This is mostly achieved by long term maintenance in form of refurbishment. Increases in dwell time, visits and money spent of between twenty percent $(20 \%)$ and forty percent (40\%) have been found to occur after a major revamp (Prinsloo 2016:1)

In South Africa, many of the shopping centres are over ten (10) years old and signs of age in the planning, tenant mix and building services are evident (Cloete 2015:495). The age and refurbishment requirements of three shopping centres selected for study were investigated, to establish their ability to meet the needs of the shoppers, tenants and objectives of owners. This research was confined to shopping centres older than thirty years and without having undergone a major revamp during the last twelve or more years, in Durban, KwaZuluNatal in South Africa. These older shopping centres which were built in the 1970s and 1980s, if not revamped, are characterised by older and outdated store layouts, a tenant mix

www.jbrmr.com A Journal of the Academy of Business and Retail Management (ABRM) 
designed around older market requirements whose demographics have changed and are tired looking because of wear and tear and possess a lot of functional and external obsolescence. In addition, most of these shopping centres are either in their maturity or declining stages of their life cycle and therefore require initiatives to initiate a new life cycle. The life cycle concept will be explained later. Failure by shopping centre owners to revamp these older shopping centres will lead to them losing customers and to the centers being classified as "dead malls".

\section{Property Life Cycle}

According to Cloete $(2016: 57,60)$, a property is a product like any other product and therefore exhibits the stages of the product life cycle viz. inception, development, maturity and scrapping/recycling. As a centre ages, physical, functional and external obsolescence sets in. (The Australian Property Institute 2015: 300). This depreciation, which may arise from physical ageing and changes in market and economic factors, competition and technology, causes the property to move from one stage to another in its life cycle. According to Nicoleta and Cristian (2009: 536) the life cycle concept provides possible explanation for the decline and emergence of different shopping centre formats.

As a property becomes older, it reaches maturity and ageing, with some properties reaching this stage sooner than others depending on wear and tear. Property income or rent will normally follow market trends and inflation, but eventually as the building ages and obsolescence sets in, rentals fall below market. The costs of maintenance also follow the same pattern of being below inflation initially but eventually tending to exceed inflation. Administration costs always follow inflationary trends. The net effect is that the property specific cash flows initially increase at a faster rate than inflation and eventually peaks and then declines (Cloete 2016: 60).

To avoid declining cash flows because of ageing, the building requires renewal or refurbishment. According to Nicoleta and Cristian (2009: 536) the life cycle concept provides possible explanation for the decline and emergence of different shopping centre formats e.g. in the United States of America where emphasis has been on life style centres

An explanation on the comparative effect of refurbishment on a shopping centre is illustrated in Figure 1 below:

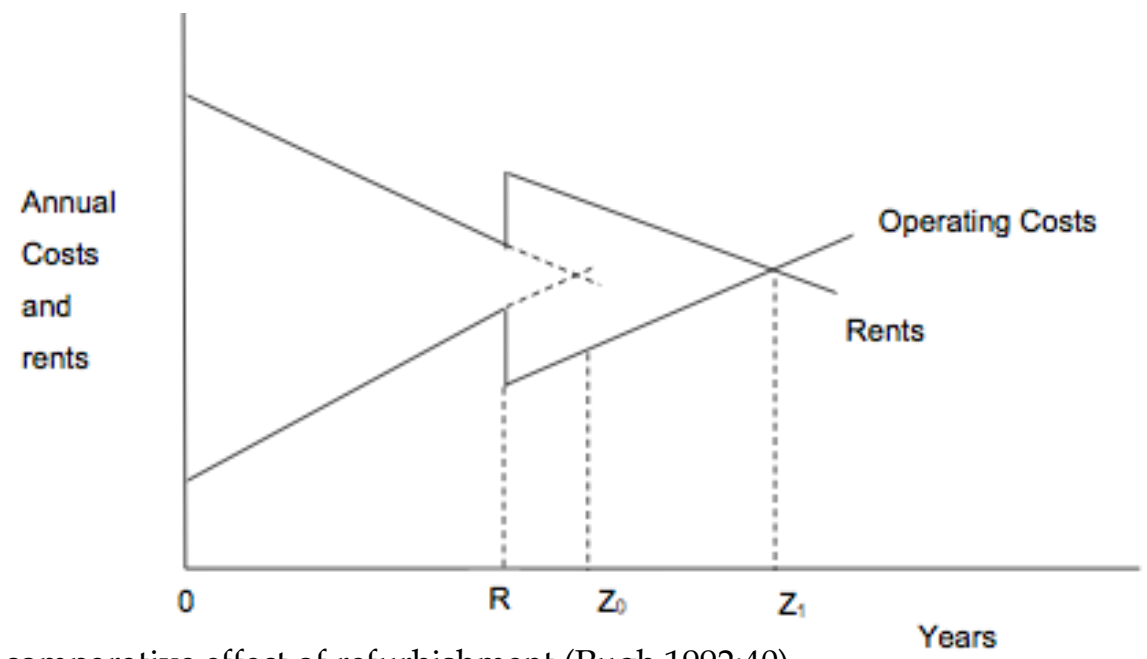

Figure 1 The comparative effect of refurbishment (Pugh 1992:40)

Figure 1 shows that as the property ages, operating costs tend to increase whilst rents fall. Refurbishment renews the building, resulting in a reduction in operating costs and an increase in rent. Refurbishment also extends that economic age of the building from $Z_{0}$ to $Z_{1}$.

\section{The refurbishment concept}

The University of Glasgow (2010: 2) defines refurbishment as "the work of renovating or renewal with an emphasis on upgrading". "Refurbishment of an aged building can enhance its market value because it can restore and improve the building condition functionally and economically" (Yau 2012: 5, cf. Chebat et al. 2014: 610) 
Refurbishment can be proactive (aggressive refurbishment) or reactive (defensive refurbishment) (Davis Langdon and Everest 1998: 3). Austrup (2015) emphasizes that "investors are looking to future proof outdated shopping centres and generate values in the second life cycle of established retail destinations".

\section{Research methodology}

This research was executed through a mixture of quantitative and qualitative approaches. To understand the importance of refurbishment, the study obtained the opinion of shoppers, tenants and centre management regarding aged shopping centres. Since shoppers and tenants are the users of shopping facilities, understanding their feelings towards the shopping centre through their conscious or sub-conscious actions and mind-set is vital in order to ensure the relevance of the shopping centre in meeting customer needs and objectives of the owners.

To complement and validate the qualitative data, visual data was used. This comprise images obtained from visual inspections, aerial photographs and building drawings. Themes and patterns were drawn based on these images and relevant data obtained through other data collection instruments.

Data collected from the sample of three shopping centres was analysed and conclusions applied on the shopping centre industry although within the limitations of this research.

\subsection{Sampling}

In this study a purposive or judgmental/convenience sample of three shopping centres in eThekwini Municipality region in KwaZuluNatal in South Africa which were older than thirty years and have not had any revamp in the last twelve years prior to commencement of this research was used. This means that generalisations will not be accurately applied to shopping centres that are not comparable in terms of size, age, location, or function.

This method involves the researcher using own judgement in choosing who can provide best information to achieve the research objectives. In so doing, the researcher requested opinion from representatives of role players in the success of a shopping centre, that is tenants, shoppers and landlords/shopping centre management as indicated Table 1.

The opinions of a total of forty-eight respondents were solicited (Table 1).

\begin{tabular}{|l|l|l|}
\hline Respondent group & Questionnaires & Interviews \\
\hline Landlord & & 3 \\
\hline Tenants & 15 & \\
\hline Customers & 30 & \\
\hline Total & 48 & \\
\hline
\end{tabular}

Table 1 Total Sample Size Respondent group

\subsection{Data collection}

Primary data for this study was obtained from landlords (property managers/ facilities managers, asset managers), tenants and shoppers. Typical information requested include current perceptions about the centre, previous refurbishment work, age of buildings, stage in property life cycle, suggested/planned improvements, and challenges. In order to obtain primary data, a mixture of face-to-face interviews, semistructured questionnaire administered by email or hand delivery was employed. Although this was a time-consuming exercise, the advantage of the personal administration at the shopping centre was to ensure that the researcher could personally request participation, explain the objective of the research and also to allow high response rate. In addition, the questionnaire is a less expensive instrument to use than interviews and it offers greater anonymity, especially where there is no face-to-face interaction.

In this research, however, these disadvantages were limited by using a more personal administration of the questionnaire, in which respondents could respond and return to the researcher without leaving the questionnaire and allowed supplementary information by ensuring that the questionnaire contained both closed and open-ended questions. Further clarifications were done by email, where necessary.

Secondary data was collected from data sources such as the SACSC Directory, text books, journals articles, previous researches, newspaper articles and the internet. Typical data obtained include property sizes, property ownership, age, location and refurbishment history. 
In addition to the above, observations and visual data were obtained. The observations were mainly based on assessing the condition of the centres and taking pictures and checking any other existing images of the shopping centres.

The research did not assess the technical and structural maintenance condition assessments in detail. Only visible structural maintenance requirements were noted. Specialist structural, architectural or any other professional assessments although important, were not part of this study.

\section{Results}

\subsection{Age and refurbishment history}

The age and refurbishment history of the shopping centres as provided by the three landlords for the three shopping centres are indicated in Figure 2. All the three centres are all over thirty years of age. One of the centres has not been refurbished since it has been built and a second centre has not been refurbished in the previous 32 years. Respondents were asked to comment about the stage of the centre in its life cycle. The life cycle stage was ascertained from the performance indicators as indicated in Table 3 below. These indicators led to the landlords suggesting the life cycle stage of their centres to be as indicated in Table 4.

The results indicate the following:

A mature centre as exhibited by trends for Centre 1 is characterised by stabilised rentals and property net income. This is attributed to shopper loyalty, but the growth could be hampered by new and emerging centres within the catchment area as highlighted by the landlord for Centre 1.

A centre in the decline stage as exhibited by Centres 1 and 2 experiences stagnant to declining property net income and tenant turnover shows a declining trend whilst the shopper visit frequency remained the same. Similarly, centres in this stage may be witnessing stagnant growth because of newer shopping centre formats as indicated by the landlord.

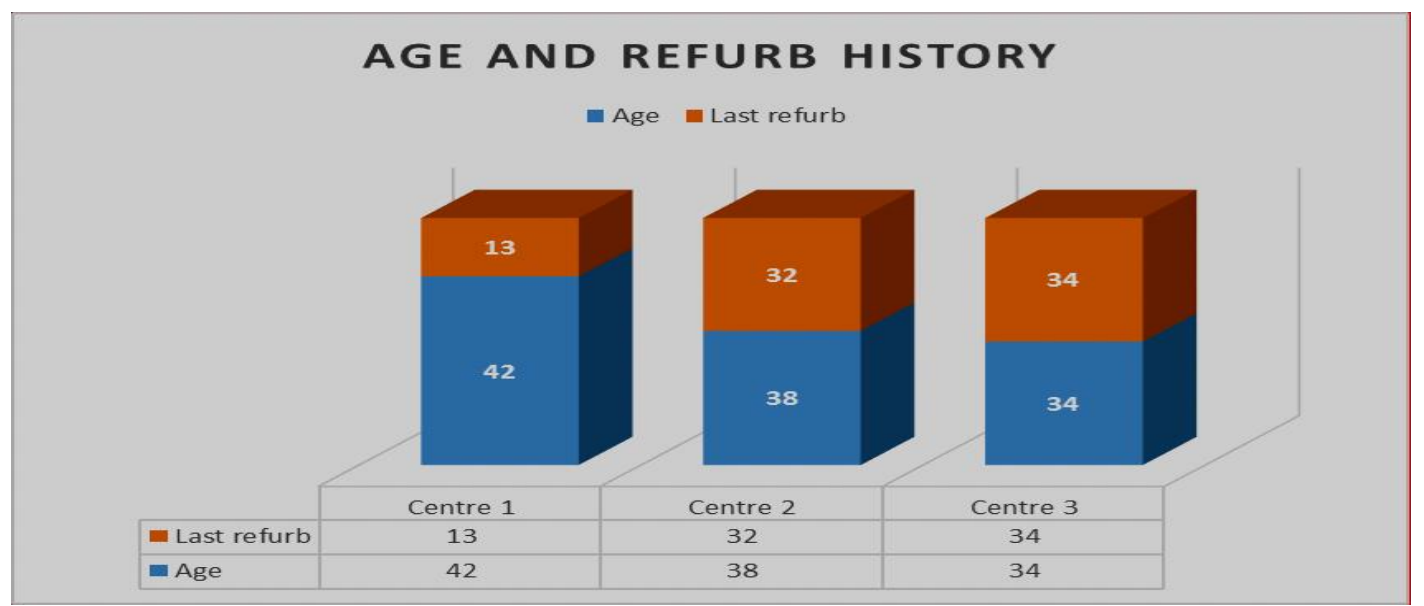

Figure 2 Age and refurbishment history

\begin{tabular}{|l|l|l|l|}
\hline Life cycle indicator & Centre 1 & Centre 2 & Centre 3 \\
\hline Net income trend & Increasing & Declining & Increasing (cost cuts) \\
\hline Pedestrian foot count & Increasing & Stagnant/declining & Declining \\
\hline Tenant turnover trend & Stable/increasing & Declining & Declining \\
\hline
\end{tabular}

Table 2 Life cycle indicators for the 3 centres

\begin{tabular}{|l|l|l|l|}
\hline Shopping centre & Age (years) & Years since last revamp & Stage in life cycle \\
\hline Centre 1 & 42 & 13 & Maturity \\
\hline Centre 2 & 38 & 32 & Decline \\
\hline Centre 3 & 34 & 34 & Decline \\
\hline
\end{tabular}

Table 3 Age of building vs Life cycle stage 
Consolidation of the above indicates that Centre 1 in this research is in maturity and Centres 2 and 3 are in decline life cycle stages. Management actions based on each centre's position in the life cycle are therefore warranted. Whilst the above time periods cannot be generalised as shopping centres are unique products which differ because of various market and physical factors, the above indicates that shopping centre performance does change from each life cycle stage to another. In the case of a maturing centre which has reached its peak performance, the next stage is decline and actions to extend this stage are required. In the case of centres already in decline stage, management actions must bring in a new life cycle can be done through a major revamp and re-tenanting.

To evaluate the necessity for revamping, the respondents were further asked of their opinion regarding current condition of the centre (Table 4).

\begin{tabular}{|l|l|l|}
\hline Respondent group & Maturity stage & Decline stage \\
\hline Landlords & Outdated & Outdated \\
\hline Shoppers & Fairly modern & Fairly outdated \\
\hline Tenant & Moderate & Outdated \\
\hline
\end{tabular}

Table 4 Shopping Centre Condition Assessment

It can be noted that a mature centre is viewed differently, showing a positive rating compared to a declining centre which is viewed mainly as outdated. While shoppers and tenants' ratings are consistent for similar life cycle stages, the landlord's rating for Centre 1 rating is not consistent with that of shoppers and tenants. This can be attributed to the in-depth knowledge he has about the centre, and its potential within the market.

Based on the opinion of the landlord, refurbishment plans for Centre 1 are in line with one of the College of Estate Management (2014:34) reasons for refurbishment, which is to stay ahead and exceed customer expectations. In addition, as mentioned above, Centre 1 is already in maturity stage, hence the landlord will desire to extend the maturity period through a refurbishment. The results for Centre 2 and 3 show that all respondents generally agree that the centres are outdated and in the declining stage. This can be explained by the fact that investors are looking into future-proofing outdated shopping centres and generate values in the second life cycle (Austrap 2015). A newer life cycle is required for shopping centres that are already in the decline stage. This new life cycle can only be initiated through a refurbishment. For a centre that is in the maturity stage, it is noted that the centre needs to concentrate on the following to avoid decline:

- Continuous preventive maintenance of existing facilities

- Plan refurbishment as the centre advances in the maturity stage and

- Refurbish in order to perpetually stay in this stage and avoid decline. This is an aggressive refurbishment which seeks to retain tenants and maintain tenants (Davis Langdon and Everest 1998:3).

For a centre which is in the decline stage, centre management efforts must be to:

- refurbish in order to return the centre back to the maturity stage.

- commence a new cycle through revamp actions such as expansion, reconfiguration, refurbishment, demolish and redevelop

\subsection{Timing and reasons for previous refurbishments}

The only centre that had been refurbished regularly was Centre 1 . The landlord explained that the centre had been revamped about eight times in forty-two years, which translates to about every 5.2 years. Four of the eight were major revamps which were conducted every ten years. The last revamp for Centre 1 was done in 2003.

It can be noted that this is in line with Chebat et al. (2014: 610) who states that a shopping mall starts to decline after fifteen years in the absence of substantial renovation. It also further aligns with Cloete (2016:60) who stated that maturity is normally reached after fifteen years of operation. However, this research has established that the life cycle of shopping centres vary depending on location, management competencies and the market environment. The life cycle of the centre induces the need for 
refurbishment whilst a satisfactory return on investment gives the stimulus to undertake refurbishment.

The absence of this stimuli during the late maturity life cycle stage is a possible reason that leads to extended periods without revamps and resulting in the so called "dead malls" or "white elephants". Landlords will therefore have to consider other actions such disposal, demolish and redevelop and change usage. Age therefore plays a less dominant role.

\subsection{Timing and reasons for possible future refurbishments}

In addition to previous revamps, an assessment of any planned revamps was undertaken to ascertain the criteria for revamp decisions which will help to establish the correct criteria for scheduling a revamp.

\begin{tabular}{|l|l|}
\hline Shopping centre & Revamp due \\
\hline Centre 1 & $2018 / 2019$ \\
\hline Centre 2 & 2017 \\
\hline Centre 3 & Unknown \\
\hline
\end{tabular}

Table 5 Timing of planned refurbishment

It was noted that the mature centre had undergone a planned refurbishment which had been necessitated by market growth of the area as well as competitive pressure from new emerging centres and another redeveloped centre.

The above factors are indicators which provide guidance for forecasting the performance of the centre and which, if nothing is done, can lead to the mature centre to move from maturity to decline.

The one centre that was in decline had a planned refurbishment which was necessitated by:

- declining net property income as pressure from newer shopping centre models is increasing. The outlook and feel of the centre therefore must be renewed.

- changes in shopping centre formats which makes hypermarkets to no longer be favoured, as their role and function is taken over by value centres.

- The third centre, that is in a decline stage, has no planned revamp despite declining performance indicators. It is worth noting that if a centre which is in a decline stage is not revamped, the cost of any attempted refurbishment will be much higher: “...if repairs are not done, then renewal or refurbishment expenses can reach five times the cost of repair..." (Vanier 2001: 7). Failure to undertake refurbishment will lead to what this research suggests as the fifth life cycle stage of shopping centres which is a "dead mall".

From the above, it can also be noted that a revamp must be planned at maturity stage of the shopping centre in order to extend the maturity stage infinitely. Shopping centres 2 and 3 required a revamp to move them back to the maturity stage. If not, continual periods of non-action may require that they are demolished and rebuilt to commence a new life cycle.

\subsection{Constraints on future refurbishment projects.}

The research also asked landlords about any challenges which may affect their intention to undertake a revamp when its due. Financial reasons were cited as the main reason for this. Further probing of respondents indicated that the motivation for a revamp is mainly based on expectancy of a return on investment. Without justifying the need through getting a satisfactory return on investment would result in failure to motivate funding for any refurbishment efforts. In addition, other financial aspects such as gearing and associated factors such as access to funds and interest rates also play a role in determining the financial feasibility of a revamp. It therefore means any refurb must be supported by a feasibility which must justify the financial sense of a revamp. A market study is also required to ascertain if the market will support the refurbished centre through analysing demographics, shopping behaviours and needs. Failure to meet this will lead to other options such as selling the building.

\subsection{Changes in spending vs age of shopping centre}

Shoppers spending behaviour has been analysed under objective 1 as it moves in harmony with the life cycle stage which affects the timing of refurbishment. It can be noted that for declining centres, the shopper spend reduces as shopper needs will no longer be met by the existing centre whilst newer and 
competing centres which are still in the inception and growth stages will attract more shopper spend. Again, it is worth noting that age is a secondary factor whilst life cycle stage provides better guideline regarding refurbishment.

\subsection{Summary of findings}

The above discussion clearly shows that the life cycle concept plays a dominant role in determining the optimum time for refurbishment rather than the physical age of the centre alone. Management actions should therefore be guided by the performance of the centre during the various stages of the shopping centre's life cycle. It has also been noted that an extended period of decline results in a "fifth life cycle stage", which is a phenomenon prevalent mostly in first world economies called "dead malls". An optimum refurbishment time takes advantage of the knowledge of the life cycle stage to reap optimum benefits from the shopping centre which would satisfy the tenants, the shoppers as well as the landlord. The ideal is to ensure that a centre does not get to the decline stage. Actions have also been suggested should the centre go beyond the maturity stage.

\section{Conclusions}

Two research questions guided this research. The first question sought to determine the importance of refurbishing aged shopping centres. From the research findings and available literature, the importance of refurbishment is as below:

- To cure obsolescence - aged shopping centres which have not been revamped are characterised by depreciation of physical building fabric and amenities. Refurbishment cures this and renew the building.

- To increase accessibility from main roads. Because of new developments around older centre which creates new traffic routes, older centres may become difficult to access. Refurbishment can improve this access. This is however not easily physically possible for existing centres because of restrictive town planning regulations and cost of the project. The owner must however do all within their power to make the centre as accessible as possible.

- To improve signage and visibility. Older centres were built when there was not much competition for shop space. The pressure for competitive positioning would not be as severe back then compared to current levels for most centres. Refurbishment is required through rebranding activities such as better and modern signage as well as designs that allow the centre to stand out.

- To compete with new shopping centres. As newer centres are built in the surrounding trade area, tenants tend not to renew their leases in older centres if they do not accommodate modern shop designs as well as modern facilities and amenities. To attract new and better tenants, the centre needs to be revamped to become attractive again. In addition, when demographics change in the trade area, the centre's offering must be aligned with new trends. For example, certain areas which have changed in terms of demographics may require new tenants and new facilities such as children play areas, gymnasium, movie houses or sports facilities.

- To expand the GLA in line with changing demographics and increasing demand. Refurbishment or expansion ensures that the centre can meet the demand for shop space.

- Improve design and building outlook. Design and layout of older buildings may appear old, dull and boring and need to be modernised so that the centre becomes an attractive shopping destination.

- Overall refurbishment results in financial gains arising from operating cost decline and improved income generating capacity of the centre. This will lead to increased property yield and capital value.

The second research question sought to ascertain the correct time to do a revamp. It was established that the timing of a revamp is dependent on the performance of the shopping centre which is mainly deduced from

- property net income trend

- tenant turnover trend

- foot traffic counts 
- vacancies and time, it takes to fill vacancies.

These factors will lead to determination of the stage of the shopping centre in the property life cycle. A suggested rule of thumb for defensive refurbishment is to undertake a revamp during the late maturity stage of the shopping centre to extend the maturity stage, or during early decline in order to return the centre to the maturity stage. Extended delays will result in a dead mall which requires extensive refurbishment or demolishing and rebuilding to begin a new life cycle. Aggressive refurbishments can be undertaken at any stage in the centre's life cycle, depending on the motivation for the refurbishment.

Literature has shown that a refurbishment can be defensive to retain tenants and maintain market share. This is typically done at maturity stage of the shopping centre. Refurbishments can also be aggressive aimed at increasing market share and rent levels by expanding the centre and improving tenant mix. This can be done at any stage of the life cycle before the decline stage. The research has noted that some of the centres that had been investigated are already in the decline stage. It was noted that these centres need revamps to start a new life cycle although it may be costlier. A framework for revamp is presented in Figure 3 as a guideline for determining optimum refurbishment time of shopping centres. This research also established that a revamp must be justified by ensuring a satisfactory return on invested funds. The returns depend on different investors. This research did not establish an acceptable rate of return to use as a rule of thumb in the current South African market environment.

There is consensus between extant literature and this research that a revamp is required when the centre is in its late maturity phase. This research gave a broad indication of refurbishment being required every seven to ten years. It is critical to once again highlight that the life cycle stage is the main indicator of the requirement for refurbishment, with the physical age playing a secondary role. In addition, the execution of the revamp decision is impacted by moderating factors such as indicated in Table 6 regarding the framework for refurbishment of centre.

Figure 3 illustrates a suggested framework for the timing of a revamp in a shopping centre:

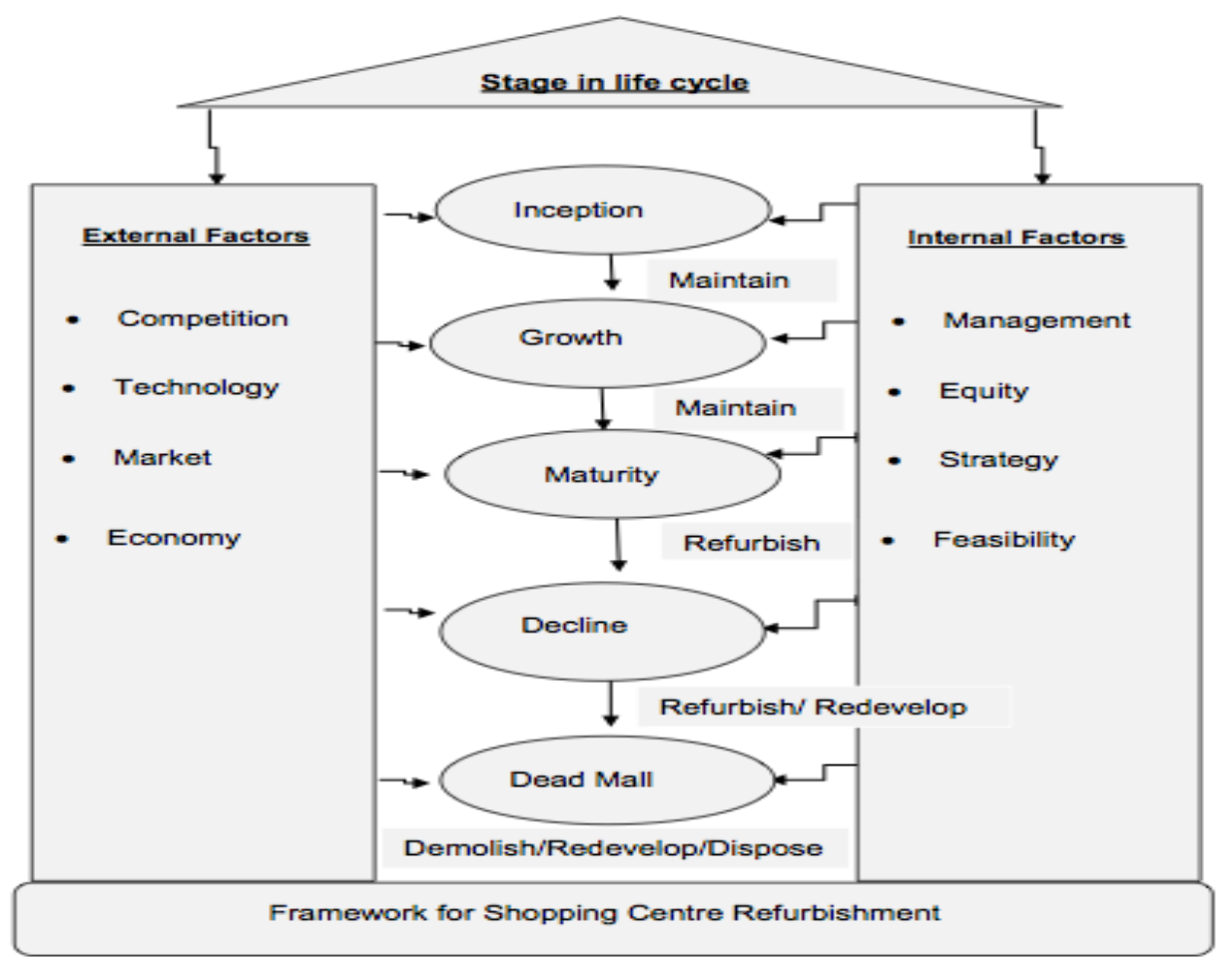

Figure 3 Framework for shopping centre refurbishment 
The suggested framework above points out that the life cycle plays a dominant role to determine optimum refurbishment time and is moderated by internal and external factors.

To use this framework, the guideline processes below are important:

- Ascertain the life cycle stage of the shopping centre

- Understand the investment strategy of the shopping centre

- Plan for refurbishment when shopping centre reaches maturity

- Perform a market and feasibility studies for refurbishment/redevelopment

- Undertake most feasible option based on life cycle stage, feasibility study and available options as per landlord strategy.

- Undertake refurbishment when centre reaches late maturity stage to extend the maturity stage into perpetuity, or

- Undertake revamp/redevelopment after reaching decline stage to commence a new life cycle.

- Consider disposal or demolish, redevelop and change use when the centre has reached dead mall status.

It has been noted in the literature and in this research conducted with three shopping centers that there is a direct relationship between the requirement for revamp and the stage in the property life cycle. The timing of refurbishment can be different for different centres but the findings at this stage indicated that most refurbishment is required to prolong the maturity stage of the centre or start a new life cycle if centre has passed decline stage. Respondents felt that intervals between refurbishment should be between seven and ten-years although most shopping centres reach maturity only after about fifteen years (Cloete 2016). The exact timing is moderated by external and internal factors as in Table 6 below. Shopping centre owners/managers must understand the stage of their shopping centres in the life cycle to position themselves through refurbishment. This is supported by Nicoletta and Cristian (2009:536) who found that the life cycle concept provides possible explanation to the decline of shopping centres and emergence of new shopping centres.

This research, whilst not exhaustive, contributes valuable information to the existing body of knowledge for shopping centre refurbishment. Complemented by further research and existing literature, it is an important toolkit to be used by asset managers and other property management professionals to enhance property returns.

\begin{tabular}{|l|l|}
\hline \multicolumn{1}{|c|}{ External Factors } & \multicolumn{1}{|c|}{ Internal factors } \\
\hline $\begin{array}{l}\text { Technological changes make building facilities and } \\
\text { amenities become obsolete and requiring renovation } \\
\text { such as green building, online shopping }\end{array}$ & $\begin{array}{l}\text { Availability of equity to undertake a revamp also } \\
\text { affects the timing. }\end{array}$ \\
\hline $\begin{array}{l}\text { Competition from new centres in the trade area affect } \\
\text { performance of the centre and need for refurb to retain } \\
\text { market share }\end{array}$ & $\begin{array}{l}\text { Competition from new centres in the trade area affect } \\
\text { performance of the centre and need for refurb to } \\
\text { retain market share }\end{array}$ \\
\hline $\begin{array}{l}\text { The market environment such as demographics in the } \\
\text { trade area affects demand and supply and requirement } \\
\text { to match changing demographics. }\end{array}$ & $\begin{array}{l}\text { Investors strategy and philosophy also affects the } \\
\text { timing/decision for revamp. Ownership holding } \\
\text { period influences the decision to refurbish or dispose } \\
\text { at maturity. }\end{array}$ \\
\hline $\begin{array}{l}\text { The economic environment affects the availability and } \\
\text { cost of capital hence funding for refurbishments }\end{array}$ & $\begin{array}{l}\text { Legal, physical, and financial feasibility tests must be } \\
\text { passed for a revamp to be conducted. If expected } \\
\text { return is not possible then a revamp may be delayed } \\
\text { or not done at all. }\end{array}$ \\
\hline $\begin{array}{l}\text { A location that offers opportunity for growth incentives } \\
\text { refurbishment whilst a poor location may not justify } \\
\text { commitment of financial resources }\end{array}$ & $\begin{array}{l}\text { Level of tenant satisfaction with premises and } \\
\text { facilities which is mainly a function of management } \\
\text { action affects centre performance and timing for } \\
\text { refurbishment. }\end{array}$ \\
\hline
\end{tabular}

Table 6 Moderating factors affecting timing of revamp 


\section{References}

Abrudan, L. (2011). Definitions and classifications of shopping centers. Marketing from Information to Decision 4: 9-20. Austrup, S. (2015). Refurbishment- transferring shopping centres into tomorrow's world. Retrieved from:

http://www.thecenterofshopping.com/blog/refurbishment-transferring- shopping-centres-into-tomorrows-world. Accessed on 30 June 2016

Chebat, J-C., Michon, R., Haj-Salem, N, and Oliveira, S. (2014). “The effects of mall renovation on shopping values, satisfaction and spending behaviour" Journal of Retailing and Consumer Services. 21(4):610-618.

Cloete, C. E. (2015). Shopping centre management in South Africa. 5th edition. Sandton: South African Council of Shopping Centres.

Cloete, C. E. (2001). Principles of property maintenance. $2^{\text {nd }}$ edition: Sandton: South African Property Education Trust.

Cloete, C. E. (2016). Property investment in South Africa. $3^{\text {rd }}$ edition. Pretoria: Manplan.

Google Maps (2017). Maps [online] Retrieved from https://www.google.co.za/maps/place/La+Lucia+Mall/@29.7537933,31.0623863,704m/data=!3m1!1e3!4m5!3m4!1s0x1ef7060e49dcb6cb:0x68a9d3ab78e1303a!8m2!3d29.753798!4d31.064575. Accessed on 30 December 2016.

Davis Langdon and Everest (1998). Shopping centre refurbishment - cost model, October 1998. Retrieved from

http://www.building.co.uk/shopping-centre-refurbishment-cost-model-october-1998/1025550.article. Accessed on 29 June 2016.

Lowry, J. R. (1997). The life cycle of shopping centres. Business Horizons Jan-Feb 1997:79.

Nicoleta, A. L. and Cristian, D. D. (2009). The life cycle of shopping centres and possible revitalisation strategies. Annals of the Faculty of Economics, University of Oradea, 4(1):536-541.

Pinto, C., Steynberg, L., Henry, P. and Van Zyl, P. (2003). Trends in retail. Architects and Specificator. Jul/ Aug 2003, 1920.

Prinsloo, D. A. (2010). Classification and Hierarchy of Retail Facilities in South Africa. [online]. Retrieved from

http:/ / www.urbanstudies.co.za/publications/ Accessed on 19 March 2016.

Prinsloo, D. A. (2016). Major retail types, classification and the hierarchy of retail facilities in South Africa. [Online] Accessed from http://www.urbanstudies.co.za/wp- content/uploads/2016/11/Classification-2016.pdf.

Prinsloo, D.A. (2015). What's new? [Online]. Retrieved from http://www.urbanstudies.co.za/publications/. Accessed on 19 June 2016.

Pugh, C. (1992). The refurbishment of shopping centres. Property Management 10(1): 38-46.

South African Council of Shopping Centres (2015). Southern African Shopping Centre Directory. Sandton: South African Council of Shopping Centres.

The Australian Property Institute (2015). The valuation of real estate. $2^{\text {nd }}$ edition. Canberra: Australian Property Institute. The College of Estate Management (2014). UK and Ireland Shopping Centre Management Sentiment Survey:2013.

University of Glasgow (2010). Maintenance and Refurbishment Policy 2010. 7 of 9.

Vanier, D. J. (2001). Why Industry Needs Asset Management Tools. Journal of Computing in Civil Engineering 15(1):35,

Yau, Mei-lee (2012). The Effectiveness of Enlivening the Shopping Centre by Asset Enhancement Projects in Hong Kong. MA Thesis. University of Hong Kong. 